\title{
Clinical Features and Diagnosis of Cardiac Sarcoidosis
}

\author{
Claudio Tana ${ }^{1, *}$, Cesare Mantini ${ }^{2}$, Iginio Donatiello ${ }^{3}$, Luciano Mucci ${ }^{4}$, Marco Tana ${ }^{5}$, Fabrizio Ricci ${ }^{2}$, \\ Francesco Cipollone ${ }^{1,6}$ and Maria Adele Giamberardino ${ }^{1}$
}

1 COVID-19 Medicine Unit and Geriatrics Clinic, SS Annunziata Hospital of Chieti, 66100 Chieti, Italy; fcipollone@unich.it (F.C.); mag@unich.it (M.A.G.)

2 Department of Neuroscience, Imaging and Clinical Sciences, Institute of Radiology, "SS Annunziata" Hospital, “G. d'Annunzio" University, 66100 Chieti, Italy; cesare.mantini@gmail.com (C.M.); fabrizioricci@hotmail.it (F.R.)

3 Internal Medicine Unit, University Hospital of Salerno, 84121 Salerno, Italy; iginiodonatiello@gmail.com

4 Internal Medicine Unit, Hospital of Fano, Azienda Ospedaliera Ospedali Riuniti Marche, 61032 Fano, Italy; luciano_mucci@libero.it

5 2nd Medicine Unit and Department of Vascular Medicine and Cardiovascular Ultrasound, SS Annunziata Hospital of Chieti, 66100 Chieti, Italy; marco_tana@yahoo.it

6 Department of Medicine and Science of Aging, and CAST, G D'Annunzio University of Chieti, 66100 Chieti, Italy

* Correspondence: claudio.tana@asl2abruzzo.it; Tel./Fax: +39-871-357905

check for updates

Citation: Tana, C.; Mantini, C.; Donatiello, I.; Mucci, L.; Tana, M.; Ricci, F.; Cipollone, F.; Giamberardino, M.A. Clinical Features and Diagnosis of Cardiac Sarcoidosis. J. Clin. Med. 2021, 10, 1941. https://doi.org/ $10.3390 /$ jcm10091941

Academic Editor: Cosima Schiavone

Received: 19 March 2021

Accepted: 13 April 2021

Published: 1 May 2021

Publisher's Note: MDPI stays neutral with regard to jurisdictional claims in published maps and institutional affiliations.

Copyright: (c) 2021 by the authors. Licensee MDPI, Basel, Switzerland. This article is an open access article distributed under the terms and conditions of the Creative Commons Attribution (CC BY) license (https:/ / creativecommons.org/licenses/by/ $4.0 /)$.

\begin{abstract}
Cardiac sarcoidosis (CS) is an unusual, but potentially harmful, manifestation of systemic sarcoidosis (SA), a chronic disease characterized by organ involvement from noncaseating and nonnecrotizing granulomas. Lungs and intrathoracic lymph nodes are usually the sites that are most frequently affected, but no organ is spared and CS can affect a variable portion of SA patients, up to $25 \%$ from post-mortem studies. The cardiovascular involvement is usually associated with a bad prognosis and is responsible for the major cause of death and complications, particularly in African American patients. Furthermore, the diagnosis is often complicated by the occurrence of non-specific clinical manifestations, which can mimic the effect of more common heart disorders, and imaging and biopsies are the most valid approach to avoid misdiagnosis. This narrative review summarizes the main clinical features of CS and imaging findings, particularly of CMR and 18-Fluorodeoxyglucose Positron Emission Tomography (18F-FDG PET) that can give the best cost/benefit ratio in terms of the diagnostic approach. Imaging can be very useful in replacing the endomyocardial biopsy in selected cases, to avoid unnecessary, and potentially dangerous, invasive maneuvers.
\end{abstract}

Keywords: cardiac sarcoidosis; imaging; biopsy; magnetic resonance imaging; 18F-FDG PET

\section{Introduction}

Sarcoidosis is a chronic disease characterized by organ involvement from noncaseating and non-necrotizing granulomas. Genetic predisposition and environmental risk factors were hypothesized as the main actors of the disease pathogenesis [1]. Lungs and intrathoracic lymph nodes are usually the sites that are most frequently affected [2,3] but no organ is spared as the involvement can be also cardiovascular, gastrointestinal, neurological and of the genitourinary system and skin [4-7].

The cardiovascular involvement is usually associated with a bad prognosis and is responsible for the major cause of death and complications, particularly in African American patients. The diagnosis is often complicated by the occurrence of non-specific clinical manifestations [8], which can mimic the effect of more common heart disorders, and imaging and biopsies are the most valid approach to avoid misdiagnosis.

This narrative review summarizes the main clinical features of CS and imaging findings, particularly of CMR and 18-Fluorodeoxyglucose Positron Emission Tomography (18F-FDG PET) that can give the best cost/benefit ratio in terms of diagnostic approach. 
Imaging can be very useful in replacing the endomyocardial biopsy in selected cases, to avoid unnecessary, and potentially dangerous, invasive maneuvers.

A literature search was conducted by searching on public databases (PubMed, Scopus). Search queries were:

Sarcoidosis AND Heart AND magnetic resonance imaging OR 18-Fluorodeoxyglucose Positron Emission Tomography OR hybrid imaging OR endomyocardial biopsy;

Sarcoid lesions AND heart AND magnetic resonance imaging OR 18-Fluorodeoxyglucose Positron Emission Tomography OR hybrid imaging OR endomyocardial biopsy;

Cardiac AND sarcoidosis AND magnetic resonance imaging OR 18-Fluorodeoxyglucose Positron Emission Tomography OR hybrid imaging OR endomyocardial biopsy;

Cardiac AND sarcoid lesions AND magnetic resonance imaging OR 18-Fluorodeoxyglucose Positron Emission Tomography OR hybrid imaging OR endomyocardial biopsy.

Papers were excluded if they were duplicated or if the topic was not adherent to the theme of cardiac sarcoidosis and magnetic resonance imaging, 18-Fluorodeoxyglucose Positron Emission Tomography, hybrid imaging or endomyocardial biopsy.

Epidemiology

The real epidemiology of cardiac sarcoidosis remains almost unknown, as clinic findings are often absent or nonspecific. Five percent of patients with pulmonary or systemic sarcoidosis can be characterized by some manifestations of cardiac involvement [9]. The prevalence can reach $25 \%$ in autopsy studies [10] and when the MRI is used as a main diagnostic technique for detection [11]. Cardiac sarcoidosis is defined as isolated (without other signs of systemic involvement) in $23-29 \%$ of total cases $[12,13]$.

These patients often have worse left systolic ventricular function and a higher incidence of ventricular tachycardia than patients with systemic sarcoidosis [14].

The extent of left ventricular dysfunction is the most important predictor of overall survival [15], and the high mortality and morbidity of cardiac involvement in sarcoidosis requires a rapid diagnosis and a prompt treatment of the condition, to avoid deterioration that can quickly become irreversible [16].

The median age of onset of cardiac sarcoidosis is 50 years [12]. Thanks to the evolution of the modern noninvasive diagnostic techniques, the detection rate has increased over the last 25 years [12].

A significant predictor of in-hospital mortality is represented by the black race, which has been associated with an increased risk of $21 \%$ (odds ratio (OR), $1.21 ; 95 \%$ confidence interval-CI-1.16-1.27 $(p<0.001))$. In these patients, the most prevalent $\mathrm{CV}$ manifestations are heart failure $(\approx 16 \%)$ and arrhythmias $(\approx 15 \%)$, while implantable cardioverter-defibrillator placement rates were $\approx 7.5$ per 1000 sarcoidosis hospitalizations (Ptrend $=0.95)[17]$.

\section{Clinical Features of Cardiac Sarcoidosis}

Clinical manifestations of cardiac sarcoidosis are correlated with the presence of typical noncaseating granulomas and inflammatory processes involving cytokine release by type 1 helper T (Th1) cells. Specifically, a high expression of Il-1 alpha, Il-2, Il-12 (localized in multinucleated giant cells and macrophages of granulomas) and IFN-gamma (in lymphocytes and endothelial vascular cells) was found in the myocardial tissue of patients with cardiac sarcoidosis [18]. The most frequent clinical symptoms are palpitations, lipothymia and the occurrence of syncope. The occurrence of sudden cardiac death is linked to arrhythmias associated with granulomas and subsequent scarring phenomena, possible foci of ectopic conduction and interruption of normal conduction or recovery pathways. Asthenia, dyspnoea and orthopnea are related to heart failure, less commonly to arrhythmias in cardiac sarcoidosis, and the involvement of the ventricle can lead to the onset of cardiomyopathy at a young age [19].

Among all arrhythmias, the most represented are those secondary to alterations of the conduction pathways (atrioventricular node, bundle of His and intraventricular pathways), 
which can progress over time as the disease evolves. According to a large population study, atrioventricular block is the most common clinical manifestation of the disease onset [20], presenting in $44 \%$ of patients with cardiac sarcoidosis [17]. The progression, even silent, towards a complete atrioventricular block can lead to clinical symptoms such as syncope, sudden death and also to ventricular tachyarrhythmias [20].

Ventricular tachyarrhythmias represent the second most common clinical manifestation of the disease onset, affecting approximately $30 \%$ of patients [12]. These include a broad spectrum of electrophysiological and clinical conditions, ranging from ventricular extrasystoles to ventricular fibrillation. Acute inflammatory mechanisms with secondary scarring and fibrotic events can determine anomalous reentry pathways based on ventricular tachyarrhythmias [21]. This hypothesis is further supported by the demonstration that ventricular tachyarrhythmias occur frequently in the first year after the introduction of corticosteroid therapy, when the inflammatory picture may not yet be completely controlled [22]. It should be emphasized that ventricular tachyarrhythmias are an independent predictor of mortality in patients with cardiac sarcoidosis [23] and require ICD implantation more frequently than in patients with dilated cardiomyopathy [24]. Sudden cardiac death is the leading cause of death related to sarcoidosis in Japan, while in America it is the second, preceded by pulmonary complications [25]. The real incidence is unknown, although it was estimated that it can occur in $14 \%$ of patients from observational studies [26]. The main mechanisms can be represented by the progression of conduction blocks or ventricular tachyarrhythmias related to the presence of granulomas. The presence of granulomas of the left ventricle was demonstrated in almost all cases, and of the interventricular septum in $94 \%$ of cases [16].

Supraventricular tachyarrhythmias have a prevalence between $19 \%$ and $32 \%[27,28]$, three times greater than in sarcoidosis patients without cardiac involvement [29]. The most frequent supraventricular tachyarrhythmia is atrial fibrillation, followed by atrial tachycardia and atrial flutter; almost all of these patients are symptomatic and the presence of the left atrial enlargement increases the risk of supraventricular arrhythmias about six times [28].

Heart failure is an onset manifestation of the disease in $16 \%$ of cases, less frequently than arrhythmias [30]. Despite this, heart failure represents one of the most important predicting factors of mortality according to the severity based on clinical NYHA classification, and instrumental (end-diastolic diameter of the left ventricle) data [23], and it is the second cause of death, only after sudden death from ventricular arrhythmias [25]. Heart failure can be caused by secondary pulmonary hypertension and/or cardiac remodeling caused by the inflammatory and scarring processes typical of the disease, leading to diastolic or systolic dysfunction.

Patients with sarcoidosis also have a 1.65 increased risk of cardiovascular events compared to the control population, after the correction for risk factors [31]. A causal connection could also be represented by the occurrence of inflammatory processes underlying both atherosclerosis and sarcoidosis. Less common mechanisms can be represented by myocardial ischemia associated with vasculitis of the coronary arteries, which are reported very rarely in the literature [32].

\section{Diagnosis of Cardiac Sarcoidosis}

The diagnostic criteria of cardiac sarcoidosis were presented by many international scientific societies and an optimal diagnostic algorithm is still under discussion.

The JMHW guidelines of 2006 [33] have suggested that a diagnosis of cardiac sarcoidosis can be reached by (1) histological demonstration of the presence of noncaseating granulomas in the myocardium in a patient with a histological or clinical diagnosis of sarcoidosis in other organs or tissues, and (2) a clinical or histological diagnosis of extracardiac sarcoidosis in association with at least three major cardiac criteria: advanced atrioventricular block (AVB), basal interventricular septal thickening and cardiac uptake of gallium-67, left ventricular ejection fraction is less than $50 \%$ for four minor criteria: (1) ECG 
abnormalities (ventricular extrasystoles, ventricular tachycardia, right bundle branch block, $\mathrm{Q}$ wave abnormalities and axial deviation on the standard electrocardiogram); (2) echocardiographic abnormalities (segmental-type morphological or wall mobility abnormalities, ventricular aneurysms, or wall thickening); (3) perfusion defects revealed by thallium or technetium scintigraphy; (4) late gadolinium reinforcement on cardiovascular magnetic resonance imaging; (5) diffuse infiltration or interstitial fibrosis in the myocardium on the biopsy.

The JMHW guidelines emphasize the importance of an endomyocardial biopsy to demonstrate cardiac involvement by sarcoid tissue. However, this approach has the great limitation of being extremely invasive in the clinical practice. Furthermore, myocardial involvement in cardiac sarcoidosis is patchy and multifocal and, when combined with the limitations of current sampling techniques, many patients can have nondiagnostic biopsies [34]. Despite its high specificity, therefore, an endomyocardial biopsy can have a low sensitivity for the diagnosis of cardiac sarcoidosis. Another limit of the JMH guidelines is that the uptake of Gallium-67 (67 Ga), still considered among the diagnostic criteria, is not currently used in most centers due to its limited diagnostic accuracy, as demonstrated by several studies [34-37].

In the latest update, fatal ventricular arrhythmias (e.g., sustained ventricular tachycardia and ventricular fibrillation) and anatomic abnormalities of the ventricular wall (e.g., aneurysm of the ventricular wall, midbasal septum thickening) were included in the major criteria, and diagnostic methods such as the 18F-FDG PET and CMR were included in the major criteria as diagnostic tools [38].

The consensus statement from the Heart Rhythm Society (HRS), in association with the American College of Chest Physicians (ACCP), the American Heart Association (AHA), the Asia Pacific Heart Rhythm Society (APHRS), the European Heart Rhythm Association (EHRA), and the World Association of Sarcoidosis and other Granulomatous Disorders (WASOG) in 2014 recognized both histological (defined) and clinical (probable) criteria for the diagnosis of cardiac sarcoidosis. These guidelines have included both the use of LGE-CMR and 18F-FDG PET in the diagnostic criteria [39].

\subsection{Patient Screening for Cardiac Involvement}

The first evaluation of patients with suspected CS should include a baseline ECG, which is useful to reveal the most common alterations. A normal ECG, however, does not exclude the presence of even minimal cardiac involvement, but is most often altered in overt CS. Echocardiography is important to reveal the most frequent, although nonspecific, abnormalities such as segmental-type morphological or wall-thickening wall hypomobility abnormalities. Such findings, however, can be found in other cardiac disorders, and are not specific to CS, but can be useful for the first screening of the severity of the disease [33].

Some abnormalities such as the cardiac right ventricular involvement can lead to the misdiagnosis of arrhythmogenic right ventricular cardiomyopathy (ARVC). The 2010 ARVC task force criteria failed to differentiate between CS and hereditary ARVC. Some authors have recently demonstrated how prolonged PR interval, advanced AVB, long duration of QRS associated with reduced LVEF, right involvement of the ventricular apex and positive findings on the 18F-FDG PET should be considered as suspected for CS [40].

\subsection{Cardiac MRI}

CMR allows a rapid, accurate and non-invasive evaluation of clinical or sub-clinical cardiac sarcoidosis, thanks to the high spatial and soft-tissue resolution [41]. At present, it is one of the preferred techniques for evaluating cardiac sarcoidosis [42,43], having a high sensitivity and specificity of $75-100 \%$ and $76-78 \%$, respectively [35], and thanks to the lack of ionizing radiation. Bright blood cine sequences allow an accurate evaluation of biventricular volume and function, mass and myocardial segment thickness (Figure 1c,d). 


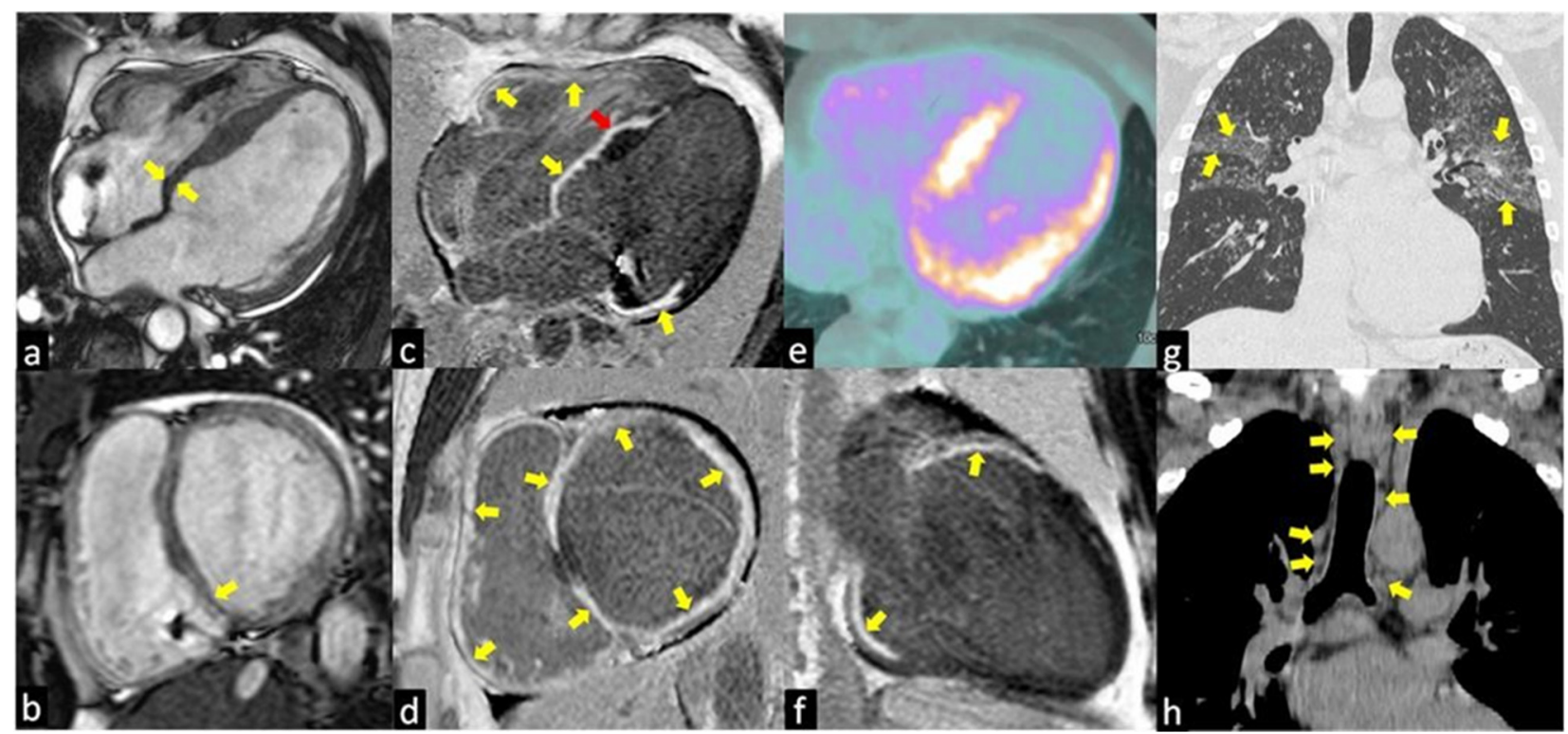

Figure 1. The images show a case of typical Cardiac Sarcoidosis characterized by the presence of LGE of all basal segments of both ventricles (yellow arrows in $\mathbf{c}, \mathbf{d}, \mathbf{f}$ ) with the predominantly transmural distribution involving more than one coronary territory and the right ventricular side of the interventricular septum (red arrow in c). Bright blood cine sequences show the thinning of the basal septum (yellow arrows in $\mathbf{a}, \mathbf{b}$ ). Coronal computed tomography (CT) scans show the typical perilymphatic distribution of micronodules with upper lobe predilection (yellow arrows in $\mathbf{g}$ ) and hilar and mediastinal bilateral lymphadenopathy (yellow arrows in $\mathbf{h}$ ). The 18F-fluorodeoxyglucose positron emission tomography (e) revealed an increased uptake in the septal and lateral left ventricle myocardial segments in a patient with systemic sarcoidosis.

With the T2-weighted images and the evaluation of early gadolinium uptake, it is possible to reveal respectively the focal presence of acute inflammation (edema) (Figure 2a) and myocardial hyperemia in the thickened myocardium where the granulomas infiltration is located (Figure 2a,b) [44]. Instead, the chronic phase is characterized by ventricular systolic dysfunctions and dilatation often associated with basal septum wall thinning (Figure 1c,d) [45].

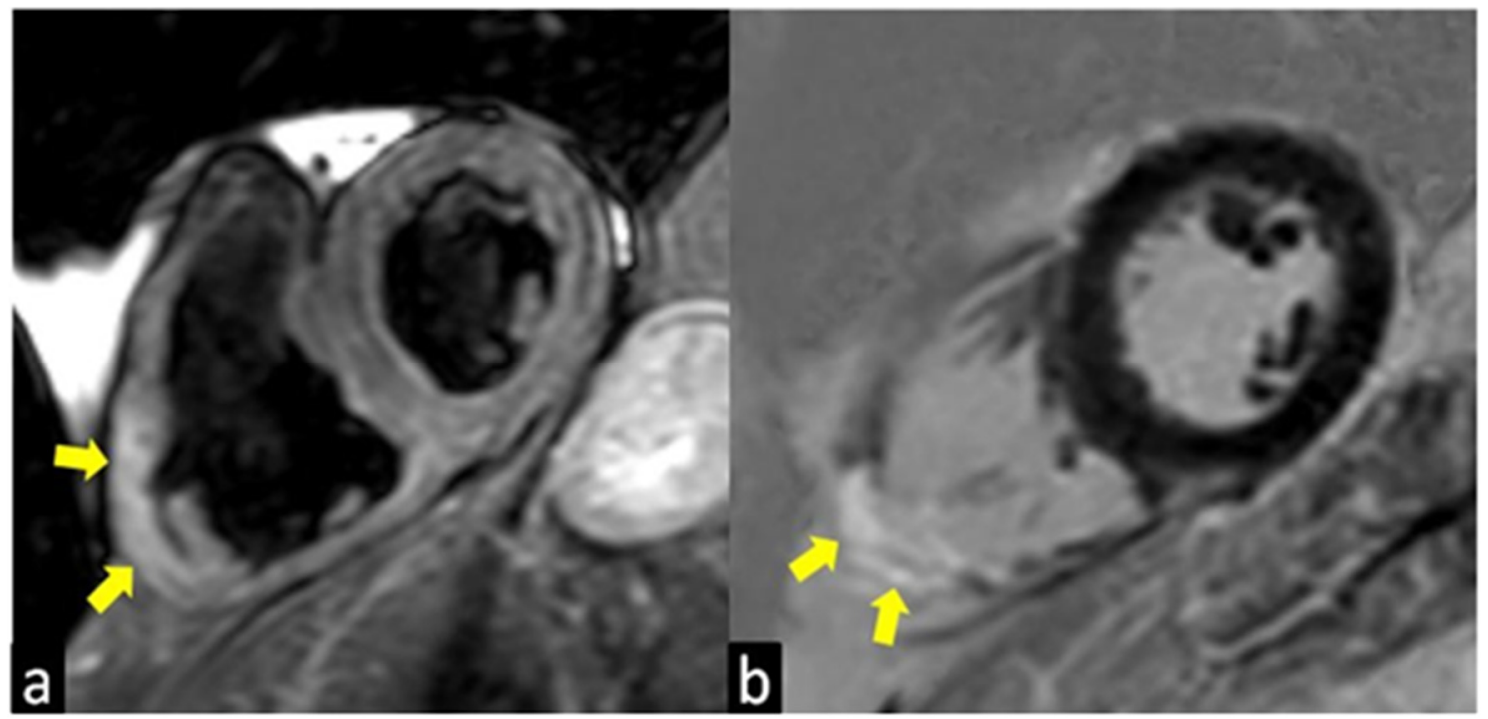

Figure 2. T2-weighted (a) and Late Gadolinium Enhancement (LGE; b) images show a case of atypical presentation of the acute phase of Cardiac Sarcoidosis, characterized by the presence of edema (yellow arrow in a) and LGE (yellow arrow in $\mathbf{b}$ ) of the inferolateral wall of the right ventricle with the transmural distribution. 
Gadolinium is a biologically inert tracer that diffuses freely into the extracellular space, but is unable to cross the intact cell membrane and exhibits a slow washout from damaged cardiomyocytes, identifying areas of myocyte necrosis during the acute phase of CS and areas of macroscopic interstitial fibrosis (scar) during the chronic phase of CS. It is important to underline that late enhancement with gadolinium is not specific for cardiac sarcoidosis but can be observed also in other infiltrative pathologies such as amyloidosis, cardiomyopathies (e.g., hypertrophic cardiomyopathy), myocarditis and ischemic lesions [46].

Typical aspects of cardiac sarcoidosis are: (1) presence of edema (acute phase) and LGE in the basal and mid interventricular septum (Figure 1c,f); (2) presence of both non-ischemic (intramyocardial or subepicardial) (Figure 1e) and ischemic (subendocardial or transmural) (Figure 1f,h) LGE patterns, the latter characterized by the involvement of more than one coronary territories [11]; (3) LGE of the right ventricular side of the interventricular septum (Figure 1e); (4) transmural LGE of thin and akinetic segments in the chronic phase of CS (Figure 1e,f) [46]. The presence of extensive LGE was associated with a poor prognosis by several studies, index of strong sarcoid activity. A meta-analysis including 7 studies and 694 subjects suggested that the presence of LGE among CS patients was associated with an increased risk of cardiovascular death or ventricular arrhythmia [47].

LGE, as well as T1 and T2 mapping techniques, can be used for monitoring the response to anti-inflammatory therapies.

CMR has some advantages over PET imaging, as there is no exposure to ionizing radiation, there is no need for patient preparation such as a specific diet prior to the image acquisition, and it also allows the assessment of cardiovascular morphology, ventricular function, valve and flow quantification $[47,48]$ and the identification of several extracardiac collateral findings $[49,50]$. However, CMR imaging is limited in patients with pacemakers, or other recently implanted metal devices, and gadolinium is contraindicated in patients with advanced renal disease (estimated glomerular filtration rate [eGFR] $<30 \mathrm{~mL} / \mathrm{min}$ ) [51].

\section{18F-FDG PET Study of Cardiac Sarcoidosis}

The 18F-FDG PET is useful in patients with sarcoidosis as it allows to distinguish normal tissues from sites of active inflammation [52]. This ability derives from the fact that Fludeoxyglucose is a glucose analogue useful for the differentiation between normal tissue and active inflammatory lesions since the activated macrophages within granulomas have a high rate of metabolic activity and glucose utilization [53]. The myocardium is a metabolically active tissue, so careful patient preparation is required before the examination. Several techniques were developed to suppress the physiological absorption of fluorodeoxyglucose by the myocardial tissue to optimize the image [53]. The Joint SNMMI-ASNC Expert Consensus paper recommends at least two high-fat meals $(>35 \mathrm{~g}$ ) and low carbohydrate content $(<3 \mathrm{~g})$ the day before the exam, followed by fasting. This technique guarantees an uptake suppression in $91 \%$ of cases $[54,55]$. A recent work reports a suppression of uptake in $95 \%$ of cases on a high-fat, low-carbohydrate diet $36 \mathrm{~h}$ before the examination, followed by intravenous unfractionated heparin [56]. The 18F-FDG PET can identify active cardiac sarcoidosis with a high sensitivity (Figure 1e) [57]. The joint analysis of the results of seven studies involving 164 patients, in which the 18F-FDG PET was compared with the standard criteria, showed a sensitivity of $90 \%$ and a specificity of $78 \%$ [57]. Similar results were obtained from a recent meta-analysis by Kim et al., which found sensitivity and specificity values of $84 \%$ of $83 \%$, respectively [58]. Specificity increases with the presence of extra-cardiac findings at total body 18F-FDG PET, such as characteristic mediastinal and/or hilar lymphadenopathy.

The 18F-FDG PET is more sensitive than gallium or thallium scintigraphy and technetium SPECT [59]. Some studies also suggest that the 18F-FDG PET can sometimes have higher diagnostic accuracy than standard clinical criteria and MRI, both for the diagnosis of cardiac sarcoidosis and for the monitoring of steroid therapy $[59,60]$. 
The 18F-FDG PET has proven to be a good technique to follow patients undergoing immunosuppressive treatment and to evaluate the therapy response, with the ability to quantify inflammation using the standardized absorption value (SUV). The 18F-FDG PET can be useful to orient the most appropriate immunosuppressive therapy, the duration of treatment and drug dosage [61-63].

The use of the 18F-FDG PET is recommended in combination with myocardial blood flow (MPI) evaluation through PET 13N (ammonia) or PET 82Rb (rubidium) in order to receive information on both the inflammatory and fibrotic components [64]. Four phases of disease can therefore be considered: normal (normal perfusion and normal absorption of 18FDG), early stage (no or slight perfusion defect with a concordant increase in 18FDG absorption), advanced stage (moderate perfusion defect with a corresponding increase in the absorption of 18FDG) and stage of fibrosis (severe perfusion defect with little or no absorption of 18 FDG) [65].

Despite these advantages, the diagnosis of CS with the 18F-FDG PET remains a challenge. Patients may have comorbidities, such as ischemic cardiomyopathy, which can make a diagnosis even more difficult. Scarring areas can be seen in both diseases, and typical inflammation areas of CS can be misdiagnosed as hibernating myocardium. The same can happen in patients with active myocarditis or systemic rheumatological conditions with cardiac involvement [57].

\subsection{Hybrid PET/CMR Imaging}

The combination of PET with CMR in a single acquisition is now possible with the emergence of new hybrid PET-CMR systems, thus the strengths of PET and CMR can be combined. Despite high costs, hybrid scanners can offer great benefits due to the high accuracy and reduced risk of complications $[66,67]$. The MRI has a high negative predictive value and excellent sensitivity in detecting fibrosis, and the PET is important for its ability to visualize and quantify inflammatory disease activity and extracardiac involvement. In limited studies, the combination of both modalities allows improved detection rates, greater accuracy, and changes in therapeutic decision making [68-70]. The association of both techniques can give additional points of evaluation of scar and inflammation findings, being useful for patient management and for the classification of various stages of the disease.

Preparation for hybrid PET/CRM is the same as for FDG-PET. The hybrid approach has the advantage of being able to remove redundant sequences to shorten exam time [71].

\subsection{Endomyocardial Biopsy}

Despite the introduction of advanced imaging techniques, endomyocardial biopsy still represents the "gold standard" for the diagnosis of cardiac sarcoidosis. However, an endomyocardial biopsy is only recommended in patients in whom it is not possible to obtain histological confirmation of noncaseating granulomas in other organs or tissues. This is because the endomyocardial biopsies have a high procedural risk and low sensitivity $(<25 \%)$ in the identification of noncaseating granulomas, first because the areas that are most frequently affected are the basal septum and lateral wall of the left ventricle, which are difficult to access for biopsy, and second because often the myocardial infiltration is focal and irregular [72]. If needed, an endomyocardial biopsy can be performed under the guidance of an electroanatomical mapping or advanced imaging techniques such as MRI [73].

\section{Conclusions}

As systemic sarcoidosis, CS remains a challenging issue in the matter of diagnostics $[74,75]$. The evolution of diagnostic techniques in recent years has led to a significant improvement in the detection and classification of the severity of the disease.

Despite the fact that the present gold standard is represented by endomyocardial biopsies, the high invasiveness and risk of false negatives suggests the need for searching 
and validating new diagnostic algorithms including non invasive methods. As increasing information is available, there is less need for an invasive diagnostic approach to reach a definitive diagnosis of cardiac sarcoidosis. We think that the use of Hybrid PET/CMR imaging could change the global approach to this harmful and complex disease in the future.

Funding: This research received no external funding.

Institutional Review Board Statement: Not applicable.

Informed Consent Statement: Not applicable.

Data Availability Statement: Not applicable.

Conflicts of Interest: The author declares no conflict of interest.

\section{References}

1. Birnie, D.; Ha, A.C.; Gula, L.J.; Chakrabarti, S.; Beanlands, R.S.; Nery, P. Cardiac Sarcoidosis. Clin. Chest Med. 2015, 36, 657-668. [CrossRef]

2. Tana, C.; Schiavone, C.; Cipollone, F.; Giamberardino, M.A. Management issues of sarcoidosis in the time of COVID. Chest 2021, 159, 1306-1307.

3. Tchernev, G.; Cardoso, J.C.; Chokoeva, A.A.; Verma, S.B.; Tana, C.; Ananiev, J.; Gulubova, M.; Philipov, S.; Kanazawa, N.; Nenoff, P.; et al. The "mystery" of cutaneous sarcoidosis: Facts and controversies. Int. J. Immunopathol. Pharmacol. 2014, 27, 321-330. [CrossRef]

4. Silverman, K.J.; Hutchins, G.M.; Bilkley, B.H. Cardiac sarcoidosis: A clinicopathologic study of 84 unselected patients with systemic sarcoidosis. Circulation 1978, 58, 1204-1211. [CrossRef]

5. Tana, C.; Tchernev, G.; Chokoeva, A.A.; Wollina, U.; Lotti, T.; Fioranelli, M.; Roccia, M.G.; Maximov, G.K.; Silingardi, M. Pulmonary and abdominal sarcoidosis, the great imitators on imaging? J. Biol. Regul. Homeost. Agents 2016, 30, 45-48.

6. Iannuzzi, M.C.; Rybicki, B.A.; Teirstein, A.S. Sarcoidosis. N. Engl. J. Med. 2007, 357, 2153-2165. [CrossRef] [PubMed]

7. Tchernev, G.; Chokoeva, A.A.; Tana, M.; Tana, C. Transcriptional blood signatures of sarcoidosis, sarcoid-like reactions and tubercolosis and their diagnostic implications. Sarcoidosis Vasc. Diffus. Lung Dis. Off. J. WASOG 2016, 33, 5030.

8. Tana, C.; Donatiello, I.; Coppola, M.G.; Ricci, F.; Maccarone, M.T.; Ciarambino, T.; Cipollone, F.; Giamberardino, M.A. CT Findings in Pulmonary and Abdominal Sarcoidosis. Implications for Diagnosis and Classification. J. Clin. Med. 2020, 9, 3028. [CrossRef]

9. Tana, C.; Wegener, S.; Borys, E.; Pambuccian, S.; Tchernev, G.; Tana, M.; Giamberardino, M.A.; Silingardi, M. Challenges in the diagnosis and treatment of neurosarcoidosis. Ann. Med. 2015, 47, 1-16. [CrossRef]

10. Tchernev, G.; Chokoeva, A.A.; Tana, C.; Patterson, J.W.; Wollina, U.; Lotti, T. Sarcoid sine sarcoidosis? A classificative, semantic and therapeutic dilemma. J. Boil. Regul. Homeost. Agents 2015, 29, 33-34.

11. Patel, M.R.; Cawley, P.J.; Heitner, J.F.; Klem, I.; Parker, M.A.; Jaroudi, W.A.; Meine, T.J.; White, J.B.; Elliott, M.D.; Kim, H.W.; et al. Detection of Myocardial Damage in Patients With Sarcoidosis. Circulation 2009, 120, 1969-1977. [CrossRef]

12. Kandolin, R.; Lehtonen, J.; Airaksinen, J.; Vihinen, T.; Miettinen, H.; Ylitalo, K.; Kaikkonen, K.; Tuohinen, S.; Haataja, P.; Kerola, T.; et al. Cardiac sarcoidosis: Epidemiology, characteristics, and outcome over 25 years in a nationwide study. Circulation 2015, 131, 624-632. [CrossRef] [PubMed]

13. Tezuka, D.; Terashima, M.; Kato, Y.; Toriihara, A.; Hirasawa, K.; Sasaoka, T.; Yoshikawa, S.; Maejima, Y.; Ashikaga, T.; Suzuki, J.-I.; et al. Clinical Characteristics of Definite or Suspected Isolated Cardiac Sarcoidosis: Application of Cardiac Magnetic Resonance Imaging and 18F-Fluoro-2-deoxyglucose Positron-Emission Tomography/Computerized Tomography. J. Card. Fail. 2015, 21, 313-322. [CrossRef]

14. Okada, D.R.; Bravo, P.E.; Vita, T.; Agarwal, V.; Osborne, M.T.; Taqueti, V.R.; Skali, H.; Chareonthaitawee, P.; Dorbala, S.; Stewart, G.; et al. Isolated cardiac sarcoidosis: A focused review of an under-recognized entity. J. Nucl. Cardiol. 2018, 25, 1136-1146. [CrossRef] [PubMed]

15. Sadek, M.M.; Yung, D.; Birnie, D.H.; Beanlands, R.S.; Nerdy, P.B. Corticosteroid therapy for cardiac sarcoidosis a systematic review. Can. J. Cardiol. 2013, 29, 1034-1041. [CrossRef]

16. Roberts, W.C.; McAllister, H.A., Jr.; Ferrans, V.J. Sarcoidosis of the heart. A clinicopathologic study of 35 necropsy patients (group 1) and review of 78 previously described necropsy patients (group 11). Am. J. Med. 1977, 63, 86-108. [CrossRef]

17. Patel, N.; Kalra, R.; Doshi, R.; Arora, H.; Bajaj, N.S.; Arora, G.; Arora, P. Hospitalization Rates, Prevalence of Cardiovascular Manifestations, and Outcomes Associated With Sarcoidosis in the United States. J. Am. Hear. Assoc. 2018, 7, e007844. [CrossRef]

18. Terasaki, F.; Ukimura, A.; Tsukada, B.; Fujita, S.; Katashima, T.; Otsuka, K.; Otsuka, K.; Kanzaki, Y.; Shimomura, H.; Fujita, M.; et al. Enhanced Expression of Type 1 Helper T-Cell Cytokines in the Myocardium of Active Cardiac Sarcoidosis. Circ. J. 2008, 72, 1303-1307. [CrossRef]

19. Ricci, F.; Mantini, C.; Grigoratos, C.; Bianco, F.; Bucciarelli, V.; Tana, C.; Mastrodicasa, D.; Caulo, M.; Aquaro, G.D.; Cotroneo, A.R.; et al. The Multi-modality Cardiac Imaging Approach to Cardiac Sarcoidosis. Curr. Med Imaging Formerly: Curr. Med Imaging Rev. 2018, 15, 10-20. [CrossRef] 
20. Nery, P.B.; Beanlands, R.S.; Nair, G.M.; Green, M.; Yang, J.; McArdle, B.A.; Davis, D.; Ohira, H.; Gollob, M.H.; Leung, E.; et al. Atrioventricular Block as the Initial Manifestation of Cardiac Sarcoidosis in Middle-Aged Adults. J. Cardiovasc. Electrophysiol. 2014, 25, 875-881. [CrossRef]

21. Kumar, S.; Barbhaiya, C.; Nagashima, K.; Choi, E.K.; Epstein, L.M.; John, R.M.; Maytin, M.; Albert, C.M.; Miller, A.L.; Koplan, B.A.; et al. Ventricular tachycardia in cardiac sarcoidosis: Characterization of ventricular substrate and outcomes of catheter ablation. Circ. Arrhythm. Electrophysiol. 2018, 8, 87-93. [CrossRef]

22. Segawa, M.; Fukuda, K.; Nakano, M.; Kondo, M.; Satake, H.; Hirano, M.; Shimokawa, H. Time course and factors correlated with ventricular tachyarrhythmias after the introduction of steroid therapy in cardiac sarcoidosis. Circ. Arrhytm. Electrophysiol. 2016, 9 , e003353.

23. Yazaki, Y.; Isobe, M.; Hiroe, M.; Morimoto, S.-I.; Hiramitsu, S.; Nakano, T.; Izumi, T.; Sekiguchi, M. Prognostic determinants of long-term survival in Japanese patients with cardiac sarcoidosis treated with prednisone. Am. J. Cardiol. 2001, 88, 1006-1010. [CrossRef]

24. Ytakaya, Y.; Kusano, K.; Nishii, N. Early and frequent defibrillator discharge in patients with cardiac sarcoidosis compared to patients with idiopathic dilated cardiomyopathy. Int. J. Cardiol. 2017, 240, 302-306.

25. Ho, J.; Chilvers, R.; Thillai, M. Cardiac sarcoidosis - an expert review for the chest physician. Expert. Rev. Respir. Med. 2019, 13, 507-520. [CrossRef]

26. Ekström, K.; Lehtonen, J.; Nordenswan, H.-K.; Mäyränpää, M.I.; Räisänen-Sokolowski, A.; Kandolin, R.; Simonen, P.; Pietilä-Effati, P.; Alatalo, A.; Utriainen, S.; et al. Sudden death in cardiac sarcoidosis: An analysis of nationwide clinical and cause-of-death registries. Eur. Hear. J. 2019, 40, 3121-3128. [CrossRef] [PubMed]

27. Fleming, H.A. Sarcoidosis of the heart. Am. J. Med. 1978, 64, 915-916. [CrossRef]

28. Viles-Gonzales, J.F.; Pastori, L.; Fisher, A. Supraventricular arrhythmias in patients with cardiac sarcoidosis: Prevalence, predictors and clinical implications. Chest 2013, 143, 1085-1090. [CrossRef] [PubMed]

29. Cain, M.A.; Metzl, M.D.; Patel, A.R.; Addetia, K.; Spencer, K.T.; Sweiss, N.J.; Beshai, J.F. Cardiac Sarcoidosis Detected by Late Gadolinium Enhancement and Prevalence of Atrial Arrhythmias. Am. J. Cardiol. 2014, 113, 1556-1560. [CrossRef]

30. Kandolin, R.; Lehtonen, J.; Airaksinen, J.K.; Vihinen, T.; Miettinen, H.; Kaikkonen, K.S.; Haataja, P.; Kerola, T.; Kupari, M. Usefulness of Cardiac Troponins as Markers of Early Treatment Response in Cardiac Sarcoidosis. Am. J. Cardiol. 2015, 116, 960-964. [CrossRef]

31. Ungprasert, P.; Crowson, C.S.; Matteson, E.L. Risk of cardiovascular disease among patients with sarcoidosis: A population-based retrospective cohort study, 1976-2013. Eur. Respir. J. 2017, 49, 1601.

32. Ward, E.V.; Nazarim Edelman, R.R. Coronary artery vasculitis as a presentation of cardiac sarcoidosis. Circulation 2012, 125, e344-e346. [CrossRef]

33. Guideline for Diagnosis of Cardiac Sarcoidosis. Study Report on Diffuse Pulmonary Diseases; Ministry of Health, Labour and Welfare: Tokyo, Japan, 1993; pp. 23-24.

34. Hulten, E.; Agarwal, V.; Cahill, M.; Cole, G.; Vita, T.; Parrish, S.; Bittencourt, M.S.; Murthy, V.L.; Kwong, R.; di Carli, M.F.; et al. Presence of late gadolinium enhancement by cardiac magnetic resonance among patients with suspected cardiac sarcoidosis is associated with adverse cardiovascular prognosis: A systematic review and meta-analysis. Circ. Cardiovasc. Imaging 2016, 9, 1-9. [CrossRef]

35. Smedema, J.-P.; Snoep, G.; van Kroonenburgh, M.P.; van Geuns, R.-J.; Dassen, W.R.; Gorgels, A.P.; Crijns, H.J. Evaluation of the Accuracy of Gadolinium-Enhanced Cardiovascular Magnetic Resonance in the Diagnosis of Cardiac Sarcoidosis. J. Am. Coll. Cardiol. 2005, 45, 1683-1690. [CrossRef]

36. Hamzeh, N.Y.; Wamboldt, F.S.; Weinberger, H.D. Management of Cardiac Sarcoidosis in the United States: A Delphi Study. Chest 2012, 141, 154-162. [CrossRef] [PubMed]

37. Tchernev, G.; Chokoeva, A.A.; Schiavone, C.D.; Erme, A.M.; Tana, C.; Darling, M.; Kaley, J.; Gianfaldoni, S.; Wollina, U.; Lotti, T.; et al. Sarcoidosis exclusion criteria: The "simple truth" for a complicated diagnosis. J. Biol. Regul. Homeost. Agents 2015, 29 (Suppl. 1), 5-9.

38. Larson, S.R.; Pieper, J.A.; Hulten, E.A.; Ficaro, E.P.; Corbett, J.R.; Murthy, V.L.; Weinberg, R.L. Characterization of a highly effective preparation for suppression of myocardial glucose utilization. J. Nucl. Cardiol. 2020, 27, 849-861. [CrossRef] [PubMed]

39. Birnie, D.H.; Sauer, W.H.; Bogun, F.; Cooper, J.M.; Culver, D.A.; Duvernoy, C.S.; Judson, M.A.; Kron, J.; Mehta, D.; Nielsen, J.C.; et al. HRS Expert Consensus Statement on the Diagnosis and Management of Arrhythmias Associated With Cardiac Sarcoidosis. Hear. Rhythm. 2014, 11, 1304-1323. [CrossRef] [PubMed]

40. Gasperetti, A.; Rossi, V.A.; Chiodini, A.; Casella, M.; Costa, S.; Akdis, D.; Büchel, R.; Deliniere, A.; Pruvot, E.; Gruner, C.; et al. Differentiating hereditary arrhythmogenic right ventricular cardiomyopathy from cardiac sarcoidosis fulfilling 2010 ARVC Task Force Criteria. Heart Rhythm. 2021, 18, 231-238. [CrossRef]

41. Pontone, G.; Di Cesare, E.; Castelletti, S.; De Cobelli, F.; De Lazzari, M.; Esposito, A.; Focardi, M.; Di Renzi, P.; Indolfi, C.; Lanzillo, C.; et al. Appropriate use criteria for cardiovascular magnetic resonance imaging (CMR): SIC-SIRM position paper part 1 (ischemic and congenital heart diseases, cardio-oncology, cardiac masses and heart transplant). Radiol. Med. 2021, 126, 365-379. [CrossRef] [PubMed]

42. Dubrey, S.W.; Grocott-Mason, R.; Mittal, T.K. Images in cardiology: Cardiac sarcoidosis with delayed enhanced MRI. Heart 2005, 91, 1185. [CrossRef] 
43. Dubrey, S.W.; Sharma, R.; Underwood, R.; Mittal, T. Cardiac sarcoidosis: Diagnosis and management. Postgrad. Med. J. 2015, 91, 384-394. [CrossRef]

44. Tadamura, E.; Yamamuro, M.; Kubo, S.; Kanao, S.; Saga, T.; Harada, M.; Ohba, M.; Hosokawa, R.; Kimura, T.; Kita, T.; et al. Effectiveness of Delayed Enhanced MRI for Identification of Cardiac Sarcoidosis: Comparison with Radionuclide Imaging. Am. J. Roentgenol. 2005, 185, 110-115. [CrossRef]

45. Greulich, S.; Deluigi, C.C.; Gloekler, S.; Wahl, A.; Zürn, C.; Kramer, U.; Nothnagel, D.; Bültel, H.; Schumm, J.; Grün, S.; et al. CMR Imaging Predicts Death and Other Adverse Events in Suspected Cardiac Sarcoidosis. JACC Cardiovasc. Imaging 2013, 6, 501-511. [CrossRef] [PubMed]

46. Nagai, T.; Kohsaka, S.; Okuda, S.; Anzai, T.; Asano, K.; Fukuda, K. Incidence and Prognostic Significance of Myocardial Late Gadolinium Enhancement in Patients With Sarcoidosis Without Cardiac Manifestation. Chest 2014, 146, 1064-1072. [CrossRef]

47. Sharma, S. Cardiac imaging in myocardial sarcoidosis and other cardiomyopathies. Curr. Opin. Pulm. Med. 2009, 15, 507-512. [CrossRef]

48. Mantini, C.; Di Giammarco, G.; Pizzicannella, J.; Gallina, S.; Ricci, F.; D’Ugo, E.; Marchetti, M.; Cotroneo, A.R.; Ahmed, N.; Bucciarelli-Ducci, C.; et al. Grading of aortic stenosis severity: A head-to-head comparison between cardiac magnetic resonance imaging and echocardiography. Radiol. Med. 2018, 123, 643-654. [CrossRef]

49. Ricci, F.; Aung, N.; Gallina, S.; Zemrak, F.; Fung, K.; Bisaccia, G.; Paiva, J.M.; Khanji, M.Y.; Mantini, C.; Palermi, S.; et al. Cardiovascular magnetic resonance reference values of mitral and tricuspid annular dimensions: The UK Biobank cohort. J. Cardiovasc. Magn. Reson. 2021, 23, 1-13. [CrossRef] [PubMed]

50. Mantini, C.; Mastrodicasa, D.; Bianco, F.; Bucciarelli, V.; Scarano, M.; Mannetta, G.; Gabrielli, D.; Gallina, S.; Petersen, S.E.; Ricci, F.; et al. Prevalence and Clinical Relevance of Extracardiac Findings in Cardiovascular Magnetic Resonance Imaging. J. Thorac. Imaging 2019, 34, 48-55. [CrossRef] [PubMed]

51. Slart, R.H.; Glaudemans, A.W.; Lancellotti, P.; Hyafil, F.; Blankstein, R.; Schwartz, R.G.; Document Reading Group. A joint procedural position statement on imaging in cardiac sarcoidosis: From the Cardiovascular and Inflammation \& Infection Committees of the European Association of Nuclear Medicine, the European Association of Cardiovascular Imaging, and the American Society of Nuclear Cardiology. J. Nucl. Cardiol. 2018, 25, 298-319. [PubMed]

52. Tana, C. FDG-PET Imaging in Sarcoidosis. Curr. Med. Imaging Rev. 2019, 15, 2-3. [CrossRef]

53. Pellegrino, D.; Bonab, A.A.; Dragotakes, S.C.; Pitman, J.T.; Mariani, G.; Carter, E.A. Inflammation and infection: Imaging properties of 18F-FDG-labeled white blood cells versus 18F-FDG. J. Nucl. Med. 2005, 46, 1522-1530.

54. Osborne, M.T.; Hulten, E.A.; Murthy, V.L.; Skali, H.; Taqueti, V.R.; Dorbala, S.; DiCarli, M.F.; Blankstein, R. Patient preparation for cardiac fluorine-18 fluorodeoxyglucose positron emission tomography imaging of inflammation. J. Nucl. Cardiol. 2017, 24, 86-99. [CrossRef] [PubMed]

55. Manabe, O.; Yoshinaga, K.; Ohira, H.; Masuda, A.; Sato, T.; Tsujino, I.; Yamada, A.; Oya-ma-Manabe, N.; Hirata, K.; Nishimura, M.; et al. The effects of 18-h fasting with low-carbohydrate diet preparation on suppressed physiological myocardial (18)Ffluorodeoxyglucose (FDG) uptake and possible minimal effects of unfractionated heparin use in patients with suspected cardiac involvement sarcoidosis. J. Nucl. Cardiol. 2016, 23, 244-252. [CrossRef]

56. Christopoulos, G.; Jouni, H.; Acharya, G.A.; Blauwet, L.A.; Kapa, S.; Bois, J.; Chareonthaitawee, P.; Rodriguez-Porcel, M.G. Suppressing physiologic 18-fluorodeoxyglucose uptake in patients undergoing positron emission tomography for cardiac sarcoidosis: The effect of a structured patient preparation protocol. J. Nucl. Cardiol. 2019, 1-11. [CrossRef] [PubMed]

57. Ramirez, R.; Trivieri, M.; Fayad, Z.A.; Ahmadi, A.; Narula, J.; Argulian, E. Advanced Imaging in Cardiac Sarcoidosis. J. Nucl. Med. 2019, 60, 892-898. [CrossRef] [PubMed]

58. Kim, S.-J.; Pak, K.; Kim, K. Diagnostic performance of F-18 FDG PET for detection of cardiac sarcoidosis: A systematic review and meta-analysis. J. Nucl. Cardiol. 2020, 27, 2103-2115. [CrossRef] [PubMed]

59. Sgard, B.; Brillet, P.Y.; Bouvry, D.; Djelbani, S.; Nunes, H.; Meune, C. Valutazione della PET FDG combinata con MRI cardiaca per la diagnosi e il monitoraggio terapeutico della sarcoidosi cardiaca. Radiol. Clin. 2019, 74, 661-671. [CrossRef] [PubMed]

60. Manabe, O.; Ohira, H.; Hirata, K.; Hayashi, S.; Naya, M.; Tsujino, I.; Aikawa, T.; Koyanagawa, K.; Oyama-Manabe, N.; Tomiyama, Y.; et al. Use of 18F-FDG PET/CT texture analysis to diagnose cardiac sarcoidosis. Eur. J. Nucl. Med. Mol. Imaging 2019, 46, 1240-1247. [CrossRef]

61. Youssef, G.; Leung, E.; Mylonas, I.; Nery, P.; Williams, K.; Wisenberg, G.; Gulenchyn, K.Y.; Dekemp, R.A.; DaSilva, J.; Birnie, D.; et al. The Use of 18F-FDG PET in the Diagnosis of Cardiac Sarcoidosis: A Systematic Review and Metaanalysis Including the Ontario Experience. J. Nucl. Med. 2012, 53, 241-248. [CrossRef]

62. Manabe, O.; Koyanagawa, K.; Hirata, K.; Oyama-Manabe, N.; Ohira, H.; Aikawa, T.; Fu-ruya, S.; Naya, M.; Tsujino, I.; Tomiyama, Y.; et al. Prognostic Value of 18F-FDG PET Using Texture Analysis in Cardiac Sarcoidosis. JACC Cardiovasc. Im-aging 2020, 13, 1096-1097. [CrossRef]

63. Furuya, S.; Manabe, O.; Ohira, H.; Hirata, K.; Aikawa, T.; Naya, M.; Tsujino, I.; Koyanaga-wa, K.; Anzai, T.; Oyama-Manabe, N.; et al. Which is the proper reference tissue for measuring the change in FDG PET metabolic volume of cardiac sarcoidosis before and after steroid therapy? EJNMMI Res. 2018, 8, 94. [CrossRef]

64. Kim, R.J.; Fieno, D.S.; Parrish, T.B.; Harris, K.; Chen, E.-L.; Simonetti, O.; Bundy, J.; Finn, J.P.; Klocke, F.J.; Judd, R.M. Relationship of MRI Delayed Contrast Enhancement to Irreversible Injury, Infarct Age, and Contractile Function. Circlation 1999, 100, 1992-2002. [CrossRef] 
65. Bogaert, J.; Taylor, A.M.; Van Kerkhove, F.; Dymarkowski, S. Use of Inversion Recovery Contrast-Enhanced MRI for Cardiac Imaging:Spectrum of Applications. Am. J. Roentgenol. 2004, 182, 609-615. [CrossRef]

66. Farber, G.; Boczar, K.; Wiefels, C.; Zelt, J.; Guler, E.C.; DeKemp, R.A. The Future of Cardiac Molecular Imaging. Semin. Nucl. Med. 2020, 50, 367-385. [CrossRef] [PubMed]

67. Furuya, S.; Naya, M.; Manabe, O.; Hirata, K.; Ohira, H.; Aikawa, T.; Koyanagawa, K.; Magota, K.; Tsujino, I.; Anzai, T.; et al. 18F-FMISO PET/CT detects hypoxic lesions of cardiac and extra-cardiac involvement in patients with sarcoidosis. J. Nucl. Cardiol. 2019. [CrossRef] [PubMed]

68. Vita, T.; Okada, D.R.; Veillet-Chowdhury, M.; Bravo, P.E.; Mullins, E.; Hulten, E.; Agrawal, M.; Madan, R.; Taqueti, V.R.; Steigner M.; et al. Complementary Value of Cardiac Magnetic Resonance Imaging and Positron Emission Tomography/Computed Tomography in the Assessment of Cardiac Sarcoidosis. Circ. Cardiovasc. Imaging 2018, 11, e007030. [CrossRef] [PubMed]

69. Wicks, E.C.; Menezes, L.J.; Barnes, A.; Mohiddin, S.A.; Sekhri, N.; Porter, J.C.; Booth, H.L.; Garrett, E.; Patel, R.S.; Pavlou, M.; et al. Diagnostic accuracy and prognostic value of simultaneous hybrid 18F-fluorodeoxyglucose positron emission tomography/magnetic resonance imaging in cardiac sarcoidosis. Eur. Hear. J.-Cardiovasc. Imaging 2018, 19, 757-767. [CrossRef] [PubMed]

70. Togo, R.; Hirata, K.; Manabe, O.; Ohira, H.; Tsujino, I.; Magota, K.; Ogawa, T.; Haseyama, M.; Shiga, T. Cardiac sarcoidosis classification with deep convolutional neural net-work-based features using polar maps. Comput. Biol. Med. 2019, 104, 81-86. [CrossRef]

71. Nappi, C.; El Fakhri, G. State of the Art in Cardiac Hybrid Technology: PET/MR. Curr. Cardiovasc. Imaging Rep. 2013, 6, 338-345. [CrossRef]

72. Dubrey, S.W.; Falk, R.H. Diagnosis and Management of Cardiac Sarcoidosis. Prog. Cardiovasc. Dis. 2010, 52, 336-346. [CrossRef] [PubMed]

73. Chapelon-Abric, C. Cardiac sarcoidosis. Curr. Opin. Pulm. Med. 2013, 19, 493-502. [CrossRef] [PubMed]

74. Tana, C.; Mantini, C.; Cipollone, F.; Giamberardino, M.A. Chest Imaging of Patients with Sarcoidosis and SARS-CoV-2 Infection. Current Evidence and Clinical. Diagnostics 2021, 11, 183. [CrossRef]

75. Tana, C.; Schiavone, C.; Ticinesi, A.; Ricci, F.; Giamberardino, M.A.; Cipollone, F.; Silingardi, M.; Meschi, T.; Dietrich, C.F. Ultrasound imaging of abdominal sarcoidosis: State of the art. World J. Clin. Cases 2019, 7, 809-818. [CrossRef] [PubMed] 